\title{
M. Yasin Taşkesenlioğlu, Tanzimat Döneminde Bir Reform Meclisi: Meclîs-i Âlî-i Tanzîmât (1854-1861), T'TK Yayınları, Ankara 2018, XXV+301 s. ISBN 978-975-16-3484-9
}

\section{Öz}

Tanzimat Dönemi'ndeki Osmanlı merkez teşkilatı ve kurumları, tarihi literatürün odağında yer almaktadır. Özellikle, Tanzimat'a damgasını vuran merkezi meclisler, birçok araştırmacının dikkatini çekmiştir. Ancak, döneminde önemli faaliyetler icra eden bu meclisler, daha ayrıntılı çalışılmayı hak etmektedir. Bu çerçevede, "Meclîs-i Âlî-i Tanzîmât"; hukuk devleti tesisi doğrultusunda, yasama-yürütme-yarg1 fonksiyonlarının kendi alanlarını belirlediği bir sürecin ürünüdür. İncelemesini yaptığımız ve Meclîs-i Âlî-i Tanzimât'ı konu alan “Tanzimat Döneminde Bir Reform Meclisi Meclîs-i Âlî-i Tanzîmât (1854-1861)" adlı kitap, literatürdeki boşluğun doldurulması açısından oldukça önemlidir.

Anahtar Kelimeler: Osmanlı Merkez Teşkilatı, Tanzimat, Merkezi Meclisler, Reform, Meclis-i Âlî-i Tanzimat.

\section{Yasin Taşkesenlioğlu, A Reform Assembly in the Tanzimat Period: Meclîs-i Alli-i Tanzîmât (1854-1861), TTK Publications, Ankara 2018, XXV+301 s. ISBN 978-975-16- 3484-9}

\section{Abstract}

The Ottoman central organization and its institutions in the Tanzimat Period are at the centre of historical literature. In particular, the central councils that made their mark on Tanzimat attracted the attention of many researchers. However, these councils, which carried out important activities in their period, deserve to be studied in more detail. In this context, "Meclîs-i Âlî-i Tanzîmât"; in line with the establishment of the rule of law, it is the product of a process in which the legislative-executive-judicial functions determine their own fields. "A Reform Council in the Tanzimat Period: High Council of Reforms (1854-1861)" the book titled; which the review we made and which is about Meclîsi Âlî-i Tanzimât, is very important for filling the gap in the literature.

Keywords: Ottoman Central Organization, Tanzimat, Central Councils, Reform, High Council of Reforms.

Tanzimat Dönemi Osmanlı merkez teşkilatı ve kurumları, Tanzimat Dönemi'ne ilişkin mevcut tarihi literatürün odağında yer almaktadır. Özellikle bu döneme damgasını vuran merkezî meclisler, yerli ve yabancı tarihçilerin dikkatini çekmiş; Stanford J. Shaw, Carter V. Findley, Mehmet Seyitdanlıŏlu, Ali Akyıldız gibi tarihçiler bu alanda çalışmalar yapmışlardır. Seyitdanlıŏ̆lu'nun Tanz̧imat Devrinde Meclis-i Vala (1838-1868) adlı çalışması dışında konu genellikle makale veya Tanzimat Dönemi'ne ilişkin çalışmaların bir parçası olarak ele alınmıştır. Ne var ki Tanzimat Dönemi'nde görevleri itibarı ile değişime uğrayan ve önemli faaliyetler icra eden bu meclisler, daha ayrıntılı çalışmalara konu olmayı hak etmektedir. Bu çerçevede Tanzimat'a karakteristik özelliğini kazandıran, çoğu reformun altında mührü olan Meclîs-i Âlî-i Tanzimat'in ele alındığ1 Tanz̧imat Döneminde Bir Reform Meclisi Mecliss-i Alìi-i Tanzimât (1854-1861) adlı çalışma, literatürdeki boşluğun doldurulması açısından oldukça önemlidir. Taşkesenlioğlu'nun 2014'te tamamlamış olduğu doktora tezine dayanan bu çalışma, giriş ve dört bölümden oluşmaktadır.

Osmanlı kanunlaştırma hareketinin mühim bir evresini teşkil eden Meclîs-i Âlî-i Tanzîmât hakkında yeteri kadar akademik çalışmanın yapılmaması ve bu meclisin parlamenter sisteme geçişte 
bir zincir halkası olarak görülmesi, yazar tarafından bu çalışma konusunun seçilme gerekçesi olarak ifade edilmiştir. Taşkesenlioğlu çalışmasında birinci elden kaynak vazifesi gören arşiv belgeleri olarak Meclîs-i Tanzîmât Defterleri, Babıali Evrak Odası Ayniyat Defterleri ve bu tasnifteki nizamnâme defterleri, Vilâyet Gelen-Giden Defterleri, Masârıfât Defterleri, iradeler ve diğer tasniflerdeki belgeleri kullanmıştır. Eserde dönemin gazeteleri olan Takvîm-i Vakayi, Ceride-i Havâdis ve Tercüman-ı Ahvâldan çıkarılan kanunlar, kanunların hazırlanış şekilleri ve üye atamaları ile ilgili bilgiler için yararlanılmıştır. Eser için dönemin önemli resmi devlet yayınları olan Düstûr ve ilgili Devlet Salnâmeler de taranmıştır ve Devlet Salnâmeleri'nin veri eksikliğinden dolayı bu iki resmî kaynağın mukayesesine gidilmiştir. Çalışmada Tanzimat Dönemi'nde etkin bir devlet adamı ve resmî tarihçi rolüne sahip olan Ahmet Cevdet Paşa'nın Tezâkir ve Ma'rûzât adlı eserlerinden bürokratik yapılanma, kanunlaştırma faaliyetleri ve Meclîs-i Âlî-i Tanzîmât hakkında faydalanılmıştır. Keza Lütfi Efendi'nin Tarih-i Lütfi adlı eserinden bu meclisin kuruluşu, nizamnâmeleri ve üyeleri hakkında bilgi edinilmiştir. Bu ana kaynakların yanında yazar, konu ile ilgili temel çağdaş kaynaklardan da istifade etmiştir. Kaynakları bu doğrultuda olan Taşkesenlioğlu, kitaba konu olan reform meclisi ile alakalı tarihsel geçmişi sunarken özellikle bazı araştırmacıların tezlerini mukayese ederek konuyu sağlam bir zemine oturtmuştur.

Eserin mahiyeti ve kaynakları belirtildikten sonra "Giriş" bölümünde; Meclîs-i Âlî-i Tanzîmât'in hangi merhaleler ve geleneğin sonucu olarak ortaya çıktığı, bu konuyla ilgili hangi terminolojik hususlara dikkat edilmesi gerektiği bağlamında bir ön-bilgi sunulmuştur. Yazarın bu bölümde aktardığı bilgilere göre Dîvân-1 Hümâyun'un Klasik Dönem’deki misyonu XVIII. yy'da değişim ve dönüşüme uğramıştır. XVIII. yüzyılın son çeyreğinde başlayan bu dönüşümde, Padişah III. Selim'in etkisi çoktur. Öyle ki tahta çıkışyla beraber iki yüz civarındaki rütbeli yöneticinin katıldığ1 Meclis-i Meşveret'in toplanmasıyla, Dîvân-1 Hümâyun'a yeni bir görünüm kazandırılmıştır. II. Mahmut ise Dîvân-1 Hümâyun'un tekelindeki yasama-yürütme-yarg1 birimlerinin kuvvetini meclislerle paylaşmıştır. Tanzimat Dönemi'ne gelindiğinde dönemle özdeşleşen bu meclislerin öneminin de arttı̆̆1 görülmektedir. Yani Sultan II. Mahmut saltanatında kurulan Meclis-i Vükelâ, yürütme yetkisini; Tanzimat sürecinde, Meclis-i Vâlâ ve Meclis-i Âli-i Tanzimat gibi danışma meclisleriyle paylaşmıştır. Bu değişim sürecinde divan teşkilatı mensuplarının yerlerini ise XIX. yüzyılda bürokratlar alsa da Osmanlı monarşik yapısının gereği, son söz yetkisi yine sultana birakılmıştır. Yazar bu bölümde, Divân-1 Hümâyun'dan evrilerek XIX. yy'a gelen yeni doğmuş bürokratik sinıfin saray dişındaki yeni yönetim merkezi olan Babıali'nin meclis kavramıyla birbirlerini beslediğini, bu kavramın Tanzimat Dönemi'nde 1854'e kadar merkezde nezaretlerin üzerinde ve nezaretlere bağh olarak iki bağlamda uygulandığını, Meclîs-i Âlî-i Tanzîmât'a da bu sürecin temel teşkil ettiğini söylemektedir. Meclîs-i Vâlâ ise "nezâretler üstü kurulan meclislerin en önemlisi ve yapısal olarak Meclîs-i Âlî-i Tanzîmât'a en çok benzeyendir." şeklinde tanımlanmıştır. Görüşülen maddelerin ekseriyete göre onaylanması veya reddedilmesi, özgürce fikirlerin konuşulması, oy eşitliği, rütbe ve siyasi gücün işleyişte belirleyici olmaması, lâyihaların tüm meclis üyelerine açık olması gibi yapısal özelliklere sahip olduğu ifade edilmiştir. İlk kez uygulanan bu usul, Meclîs-i Ẩlii Tanzîmât'ın çalışma prensiplerini de teşkil edecektir. Tanzimat'in meclislere ivme kazandıran etmeni olarak ise yazar, Mustafa Reşit Paşa'yı göstermektedir. Önceki dönemlerdeki danışma organlarının merkezinde padişah etkili iken, Tanzimat ile devlet adamlarnın atılımları ön plandadır ve devre şekil veren onlardır. Reşit Paşa'nın usûl-ü meşvereti, kurumsal kimliğe evirmesi de bunun en önemli kanıtı olarak gösterilmiştir. Yazar, Tanzimat eksenini teşkil eden kanunlaştırma bareketinin temelleriyle ilgili örfi yani şeriatın dışındaki padişah bükümlerinin padişahın kanun yapma/koyma yetkisi olarak tanımlanmasına ve bunun şeri bukuka paralel olarak geliştiğine, özellikle Klasik Dönem Osmanlısında ise padişahın örfi hukuk ekseninde yasama gücünün genişlemesine ve bunun şeriatın verdiği hakla yapıldığına değinmiştir. Devamında konu özünün kavranılması adına kanunname, nizamname, mą̧bata, lâyiha, kanunlaştırma/taknîn/legislation, tedvîn/codification, resepsiyon gibi hukuki terminolojiye ayrıntılarıyla yer verilmiştir. Bu bölüm; Tanzîmât-1 Hayriye'nin ilan edilme sürecine, 
fermanın içeriğine, kanunlaştırma ve reform faaliyetlerindeki konjonktürel ve diş politik etkilerin mahiyetine değinilerek çeşitli isimlerin bu konuya dair fikirlerinin mukayesesi ile tamamlanmıştır (s. 1-23.).

“Tanzimat Döneminde Merkezi Danışma Meclisleri ve Meclîs-i Âlî̀-i Tanzîmât” adlı birinci bölümde Taşkesenlioğlu, II. Mahmut Devri'nde teşkil olmuş merkęৃ̂̂ danışma meclislerinden 1854'e kadar devam edenleri inceleyerek konunun öncesine 1şı tutmuş, yerleşmeye başlayacak olan meclis geleneğinin merhalelerine değinmiş ve Meclîs-i Âlî-i Tanzîmât'ın temel yapısını oluşturan öncülleri ayrıntılarıyla okuyucuya sunmuştur. Bu bağlamda Sultan III. Selim Dönemi’ndeki Meclîs-i Meșveret in yerini, Sultan II. Mahmut'un sadraz̧amlık makamını başvekâlete devretmesinden sonra Meclîs-i Vükelâ almaya başlamıştır. Haftada iki gün toplanan, Meşveret Meclisi'nden farklı olarak mesai ile çalışan, yasama ve yürütmenin en yüksek merciindeki bu meclisin Babıali'de toplanıp nezaretlerin yürütme görevlerini kontrol etmek, yasama işlerini görüşüp karara bağlamak gibi mesuliyetleri vardı. Sultan Abdülmecit'in tahta çıkmasından sonra bu meclisin üyelerinin tamamı sultan tarafindan atanmıştır. Hazırlanan kanunlar padişaha sunulmadan önce kabul, ret veya tashih için bu meclise sunulmuş, sadrazamın arz tękiresi vasıtasıyla da padişah son kararı vermiştir. Meclîs-i Âlî-i Tanzîmât da görev yaptığ1 dönemde bu meclisle yasama alanında beraber çalışacaktır.

Meclìs-i Valâ-yı Abkâm-ı Adliye'nin ise Tanzimat'ın hemen öncesinde II. Mahmut tarafindan kurulup, ilk etapta reformlar üzerine yeterince çalışma yapamadığı aktarılmıştır. Meclîs-i Vâlâ'nın oluşum sürecine değinen yazar; Mustafa Reşit Paşa'nın meşrutî yönetimlerle idare edilen İngiltere ve Fransa'daki meclislerden ziyade, monarşik Avusturya ve Prusya'nın meclislerini örnek aldığını ifade etmiştir. Meclîs-i Vâlâ'nın yapısal özellikleri; layıhaların tüm üyelerce incelenebilmesi, fikirlerin isim sırasına göre özgürce konuşulması, parlamenter sistemlere usulen benzeyiş, üyeler arası rütbe ayrımının olmaması, oy eşitliği ilkesinin sağlanmaya çalışılması şeklinde aktarılmıştır. İlk kurulduğunda sarayda meclis için bir yer tahsis edilmişse de fermanın ilanından sonra meclisin yeri Babıali’ye taşındı. Meclis üzerine yüklenen umur ve reformların üstünden meclisin kalkamadığını ifade eden yazar, bunun bürokratik yetersizlikten kaynaklandığını akabinde de tanzim yoluna gidildiğini aktarmıştır. Meclîs-i Vâlâ’nın yetki alanı, Meclîs-i Âlî-i Tanzîmât kurulduktan sonra daralmış, kurumsal dönüşüme uğramış, daha çok küçük devlet memurlarının azli ve atama işleri, adli ve mülki meselelerle ilgilenmiştir. Tanzimat Fermanı'nın ilanından önce Meclîs-i Vâlâ'nın yetki alanı dışında kalan tanzim meseleleri için II. Mahmut Dönemi'nde, Dâr-ı Şûrâ-yı Bâbıâli adında yine bir merkezî danışma meclisi kurulduğunu aktaran Taşkesenlioğlu; bu meclisin askerlik mevzuatı dışındaki umurla ilgilendiğini, yapısal olarak Meclîs-i Vâlâ'dan dahi üstün olacak olan Meclîs-i Âlî-i Tanzîmât ile özdeştirilmemesi gerektiğini, kısa ömürlü olduğunu ve derli-toplu bir nizamnâmesi olmayışından yasamadaki etkisinin tespitinde zorlanıldığını eklemiştir. Kuruluş tarihi bilinmeyen Meclîs-i Âli-i Umûnî ise; Tanzimat reformlarını görüşen üst düzey bir danışma organı mahiyetindeydi ve Tanzimat'ın ilanından sonra vükelâ ve üst düzey devlet adamlarının katıldığ1 genel bir meclis olarak Meclîs-i Vâlâ’nın aldığı kararları değerlendirmekle mükellefti. Meclîs-i Vâlâ'nın yasama yetkilerini Meclîs-i Âlî-i Tanzîmât’a devrettikten sonra ise bu meclisle çalıştığını belirten yazar, 1854 yılına kadarki merkezi danışma meclislerini ana hatlarıyla ele almıştır. Taşkesenlioğlu takip eden başlıkta Meclîs-i Âlî-i Tanzîmât'ın kurumsal olarak alt yapısını oluşturan etmenleri konunun daha iyi idraki için ortaya koymuştur (s. 25-35.).

Taşkesenlioğlu, Meclîs-i Âlî-i Tanzîmât'ın kuruluşunu hızlandıran esas sebebin Tanzimat'ın bir nevi mottosu diyebileceğimiz “Osmanlı'nın eski gücüne döndürülmesi fikri temelinde, kanunlaştırma hareketi” olduğunu, ikincil sebepleri ise harici-dahili politiğin teşkil ettiğini aktarmıştır. 1853-1856 Kırım Harbi sonrası Rus diplomasisinin baskılarıyla Osmanlı Devleti’nin bu baskıdan bürokratik olarak da olumsuz etkilenmesi, Sinop'taki Osmanlı donanmasının Ruslarca yok edilmesi Osmanlı'y1 siyaseten Batı Avrupa'ya itmiştir. "Tanzimat hareketine yeni bir ivme kazandıracak olan Meclîs-i Âlî-i Tanzîmât'in kuruluşu da bu devirde gerçekleşmiştir." Sonrasında Islahat Fermanı bu politik eksene kaymanın (özellikle İngiltere) gereği sonucu ilan edilip Paris Barış 
Konferansı'na yetiştirilmiş, Osmanlı artık Avrupa diplomasisinin bir parçası olmuştur. Yazarın ifadesiyle Islahat Fermanı'yla yabanc1 sermayenin nüfuzunun artmas1, gayrimüslimlerin bürokrasideki varlığının çoğalması, demiryolu-madencilik-liman işletmesi gibi yatırım alanlarında İngiliz ve Fransız sermayesi tahakkümü meclislerin iş yükünü de doğrudan etkilemiştir. Devamında hapishanelerin 1slahı, gayrimüslim çocuklarının Osmanlı okullarına alınması gibi Islahat Fermanı'nın önünü açtığı ve Meclîs-i Âlî-i Tanzîmât'n da düzenlemelerini yaptığı spesifik değişikler de örnek olarak sunulmuştur. Yazar, her ne kadar diş-politik tahakkümün mevcut olduğunu kabul etse de İngiltere'nin, Osmanlı büyükelçisi Canning’in, Babıali’nin reformlara hız vermesi gerektiği, söyleminin bu reform meclisinin kurulmasında çok da etkili olmadığ1 görüşünü aktarmıştır. Taşkesenlioğlu, meclisin kuruluşunu etkileyen bir diğer mesele olan "Tatbik Mührü Meselesi ve Rüşvetle Mücadele" başliğı altında Mustafa Reşit Paşa ve kendisinin onun tarafından sadrazamlıktan alındığını düşünen Mehmet Ali Paşa arasındaki rüşvet iddiaları tartışmalarını aktarmıştır. Mehmet Ali Paşa'nın rüşvet aldığı iddiaları aktarılmış ve onun dava edilebilmesi, Meclîsi Âlî-i Tanzîmât'ın kurulmasının gizli sebebi olarak belirtilmiştir. Yazar, Sultan Abdülmecit'in de bu meclisin hazırlık aşamasında ve Tanzimat'n rükünlerinin gerçekleşebilmesi için rüşvetle mücadelenin önemini vurguladığına dikkat edilmesi gerektiğini belirtmiştir (s. 35-43.).

Rüşvetle mücadele ve mülki-askeri-bahriye-maliyeye dair gereken hususların bu noktada tanzim edilip reformların hız kazanması adına Sultan Abdülmecit'in 7 Eylül 1854'te yayınladığı hatt1 hümâyunuyla meclisin kurulma çalışmaları başlamıştır. Meclîs-i Umûmî'de tasdik edildikten sonra üye ataması için sadrazam konağında yapılan toplantıda, üyelerde aranan özelliklere değinen yazar; Özellikle Mustafa Reşit Paşa ve çevresindekilere oranla daha muhafazakâr olanlar ile süregelen siyasi rekabetin bu seçimde de ön planda olduğunu, hariciye kökenli, reformist kişilerin merkezî meclislere tercih edilmesinin bu siyasi rekabetin gereği olduğunu ifade etmiştir. Eski Serasker Mehmet

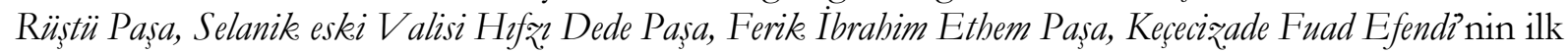
üyeler, Hüdavendigar V alisi Mehmet Emin Ali Paşa'nın meclis başkanı, Rüssti Molla Efendìnin de meclis müftüsü olarak atandığını ve 8 Ekim 1854'te Meclîs-i Âlî-i Tanzimât adıyla Babıali'deki Meclis-i Maarif dairesinde, Lütfi Efendi'nin değimiyle meclis-i mevcudenin ma-fevkinde olarak bu reform meclisinin resmen açıldığını aktarmıştır. Yazar; Meclîs-i Âlî-i Tanzîmât'ın, tüm meclisler üzerinde bir meclis olduğunu, memur ve erbâb-1 vukûfa kanun tasarısı imkânını tanıdığını, Meclîs-i Vâlâ yüksek yargı organı ve Babıali yürütme kuvvetinde iken bu meclisin de yasama gücünü elinde bulundurduğunu belirtmiştir. Meclîs-i Âlî-i Tanzîmât'in; Tanzimat sürecini ilgilendiren bütün konularda merkezi bir müzâkere uzvu olduğunu ve Meclîs- i Vâlâ'nın yürüttüğü Tanzimat işlerinin büyük bir kısmını devraldığını aktarmıştır. İlk düzenlediği kanun "Men'-i İrtikâb Kanûnu” olan bu reform meclisinin iç tü̃üklerine değindikten sonra yasama sürecinin nasıl işlediğine dair tematik bir şema sunulmuştur. Tanzimat'ın kanunlaştırma merkezli uygulamalarının taşraya tam anlamıyla uyarlanamaması ve neticesinde kurulan "Islahat-Teftiş Komisyonları"nın Rumeli ve Balkanlar olmak üzere yaptıkları teftiş hareketleri değerlendirilmiştir. Devamında reform meclisinin "Yarg1 ve Ticarî İmtiyazlardaki Yetkileri”ni ele alan yazar; bu bölümü, "1856 Meclîs Nizamnâmesi” ve "Dönem Hakkında Bir Değerlendirme" yaparak sonlandırmıştır (s. 43-97.).

"Meclîs-i Âlî-i Tanzîmât'ın Bürokratik Yapısı" adlı ikinci bölümde yazar, Meclîs-i Âlî-i Tanzîmât ve Meclîs-i Vâlâ’nın "başkanlar"ının üst düzey ve reformları destekleyen devlet adamları arasından seçildiğini belirtmiştir. Ali ve Fuad Paşalarnn ilk başkanlıkları döneminde Meclîs-i Âlî-i Tanzîmât başkanlığının Hariciye Nâzırlığı uhdesinde olduğu yani Ali ve Fuad Paşaların, hem Hariciye Nezâreti, hem de Meclîs-i Âlî-i Tanzîmât başkanlığı görevini beraber yürüttüğü ifade edilmiştir. Bu ikili görev uygulamasının Tanzimat umurunu sekteye uğratacağı düşüncesi ile bir süre sonra Kıbrıslı Mehmet Paşa'nın başkanlığa atanmasıyla, meclis başkanlığı görevinin bağımsızlaştığı aktarılmıştır. Reform meclisinin dönemin politik gelişmeleriyle doğrudan alakalı olduğunu belirten yazar; sadaretteki değişimlerin Meclîs-i Âlî-i Tanzîmât ve Hariciye Nezâreti'nde görev değişikliklerine neden olduğuna dikkat çekmiştir. Devamında Reşid Paşa'nın Stratford Canning’in 
desteğiyle birkaç defa sadarete gelmesinin; Ali Paşa'nın Hariciye Nâzırı, Fuad Paşa'nın da Meclîs-i Âlî-i Tanzîmât başkanı olmasıyla sonuçlandığına vurgu yapmıştır. Taşkesenlioğlu, bu konu hakkında Cevdet Paşa'nın aktardığı bilgilerin dikkate değer olduğunu ve meclis başkanlı̆̆1 seçimlerinin, diğer kademelerde olduğu gibi iç çekişmelere alet edildiğini belirtmiştir. Meclîs-i Âlî-i Tanzîmât "üyeleri”"nin ise başkanın önerisi ve vekillerin bazılarının fikirleri doğrultusunda atandığ1 ancak başkanın teklifi olmadan nüfuz sahibi devlet adamlarının etkisiyle de meclise üye atandığı aktarılmıştır.

İlk kez Sultan II. Mahmut Dönemi’nde, idari işler ve hazırlanan kanunların şeri hükümlerle çelişmemesi adına merkezde kurulan meclislerde birer "müftünün" görev aldığ1 ve devamında müftünün kararlarda istişarî bir sorumluluk üstlendiği fakat siyasi iradeyi değiştirebilecek gücünün olmadığı belirtilmiştir. Ağırlıklı olarak Islahat Fermanı'ndan sonra Osmanlı topraklarında çeşitli yatırımlar için yabancıların bir kısmının sadarete bir kısmının doğrudan Meclîs-i Âlî-i Tanzîmât'a imtiyaz başvuruları yapması, başvuruların Türkçeye çevrilme ihtiyacını ortaya çıkarmıştır. Bu ihtiyaç üzerine kurulduğu ifade edilen "Tercüme Odası"nın Fransa başta olmak üzere, İngiltere ve Avusturya gibi devletlerden numune olarak alınan kanunların çevirisi göreviyle reform meclisinin iş yükünü paylaştığı aktarılmıştır. Devamında yazar, Meclîs-i Âlî-i Tanzîmât üyelerinin rütbeleri ve "çalışma günleri”ni incelemiş üye maaşları hakkında tablolar aracılı̆ğ ile bilgi vermiştir. Ayrıca, Meclîs-i Âlî̀-i Tanzîmât'a bağll “daire ve odalar” incelenmiş, bürokratik işleyiş üzerinden meclisin tanzim ettiği defterler ve evrak içerikleri hakkında bilgi verilmiştir. Yazar, II. Mahmut devrinde merkezî meclislere mahsus şekilde kullanılmaya başlanan mühürlere değinmiş ve "Meclîs-i Âlî-i Tanzîmât mührü"nün meclisin açılmasından bir sene sonra yaptırıldığına dikkat çekmiştir. Taşkesenlioğlu bu bölümü, Meclîs-i Âlî-i Tanzîmât'n diğer kurumlarla ilişkilerini tahkik ederek bitirmiştir (s. 99-148.).

"Meclîs-i Âlî-i Tanzîmât'ın Faaliyetleri” adlı üçüncü bölüm üç alt başlığa ayrılmış olup "Kıbrıslı Mehmet Paşa'nın Bir Islahat Lâyıhâsı" adlı birinci başlıkta yapılması düşünülen reformların şu şekilde sıralandığ1 aktarılmıştır: Vakıf gelir ve giderlerinin kontrol altına alınması, tebaanın din-mezhep ayrımı yapılmaksızın askerî ve idarî anlamda istihdamı, zaptiye memurunun jandarma usulüne göre tanzimi, madenlerle alakalı bir nizamnâme yapılması, cizyenin düzenlenmesi, gümrük ve karantina hizmetlerinde tanzim, bekçilerin istihdamı, ziraatın gelişimi için memur vasıtası ile halkın teşviki, demiryolu yapımına başlanılması, medrese eğitiminin 1slahı, İstanbul'daki dükkan ve hanlardan vergi alınması, ormanların korunması, kara ve deniz askerlerine üniforma tahsisi ve asker sayılarının tanzimi, mühimmat temini, liyakat ve tasarrufa gidilmesi. "Merkez Teşkilatı'ndaki Düzenlemeler" başlı̆ğ altında ise; kazalardaki adlî-askerî rütbeler, naiplik, şer'iyye mahkemeleri, gayrimüslimlerin askerliği, vakıf odalarının kaldırılması, kanun niteliği kazanan mazbatalar, Meclîs-i Muhtelit, Maarif-i Umûmîye Nezâreti'nin ve Mekteb-i Mülkiye'nin kuruluşu, 1857 Matbûât Nizamnâmesi, Osmanlı madenleri hakkındaki ilk girişimler, Maden Nizamnâmesi, Zabtiye Nezâreti'ne dair düzenlemeler, ilk bütçe nizamnâmesi, Meclîs-i Muhasebe, vergi düzenlemeleri, Meclîs-i Maabir'in ve Ticaret Mahkemeleri'nin kuruluşu, Şehremaneti'nin ve Altınc1 Daire-i Belediye'nin kuruluşu hakkında bilgiler verilmiştir. Üçüncü başlık olan "Diğer Faaliyetler"de yazar; idarî-mülkî alandaki düzenlemeleri, Men’-i İrtikâb Kanûnu, 1858 Arazi Kanûnu ve Tapu Nizamnâmesi, 1858 Ceza Kanunu, Metn-i Metin Komisyonu, liman-nehir-karayolu, orman ve demiryollarındaki düzenlemeleri, Kırım-Kafkas muhacirlerinin sevk ve iskânı, Bosna-Hersek isyanları ve Çiftlikat Kanûnu, inhisar düzenlemeleri, hapishanelerin sslahı meselelerine dikkat çekmiştir (s. 150-237.).

“Meclîs-i Âlî-i Tanzîmât'ın Meclîs-i Vâlâ ile Birleşmesi ve Yasama İşlerinin Seyrì" başlıklı dördüncü bölümde Meclîs-i Âlî-i Tanzîmât'ın Meclîs-i Vâlâ ile birleşme nedenleri iç ve diş olarak iki etmende incelenmiştir. Bu iki meclisin birleşmesinde, İngiliz elçisi Henry Bulwer'in baskının etkili olduğuna dair Engelhardt'ın görüşünü aktaran yazar bunu "çarpıcı bir iddia” olarak nitelendirmiştir. Bulwer, konsolosluklar aracılığıyla taşradaki uygulamalar hakkında araştırmalar 
yaptırmış ve bir genelge yayınlamıştı. Reformların etkin uygulanmadığına ve Islahat Fermanı'nın gereklerinin yerine getirilmediğine dair Osmanlı Devleti'ne gönderilen notanın Bâbıâli'ye bir tavsiye niteliğinde olduğu belirtilmiştir. Yine aynı şekilde, Çarlık Rusya'nın Bosna-Hersek bölgesindeki uygulamaların yetersizliğine dair Osmanlı Devleti'ne bask1 kurması, hatta İngiliz elçisinin yaptı̆̆1 tekliflerin de Rusların baskılarını önlemek amacıyla olduğuna dair Engelhardt'ın görüşleri değerlendirilmiştir. Devamında yazar, Engelhardt'ın 'Babıali yönetimi (ve yeni Padişah), baskılar karşısında daha fazla direnemeyip Meclîs-i Âlî-i Tanzîmât'ın yetkilerinin bir kısmını kaldırıp diğerlerini de birleştiği Meclîs-i Vâlâ’ya devretti." şeklindeki yorumuna dikkat çekmiştir. Meclîs-i Âlî-i Tanzîmât'ın 1861 yılında Meclîs-i Vâlâ ile birleşmesinin dahili nedeni olarak; reformların ihtiyaçlarına cevap verememesi, iki meclis arasındaki yetki karmaşası ve Meclîs-i Vâlâ'nın gereğinden fazla kalabalık, hantal bir yapıya sahip olması üzerinde durulmuştur. Ayrıca, Sultan Abdülaziz’in, her iki meclisin devletin ihtiyaçlarına karşlık veremediği, zorluk ve gecikmelerin yaşandığ1 gerekçesiyle ve tahta yeni çıkan her sultanın yaptı̆̆ı düzenlemelerden kaynaklı bir karar olduğu eklenmiştir. Nihayetinde, Sultan Abdülaziz'in, 14 Temmuz 1861 tarihli hatt-1 hümâyunu ile Meclîs-i Ahkâm-1 Adliye'nin kurulmasıyla idarî ve adlî güç yani yasama ve yarg1 tekrar birleşirken; yeni meclisin mülkiyye, kavânin ve mubakemât olarak üç kısma ayrıldığı, başkanlığına Hariciye Nazırı Fuad Paşa'nın getirildiği ve önceki meclislerin ricâl ve devlet memuru yargilama yetkilerinin kısıtlanıp yeni meclis bünyesinde kurulan Mubakemât Dairesi'ne; Meclîs-i Âlî-i Tanzîmât'nn kanun ve nizamnâme lâyıhâsı yapma yetkisinin Kavânin ve Nizamât Dairesi'ne, Meclîs-i Vâlâ'nın mülkî sorumluluğunun da Mülkizye Dairesi'ne devredildiği ifade edilmiştir. Yazar, Kavânin ve Niz̧amât Dairesi'nin Meclîs-i Âlî-i Tanzîmât'ın nizamnâme ve kanun yapma, gelen layihaları değerlendirme ve denetleme yetkisini devraldığını aktarırken; meclisten havale edilen yasamayla ilgili yazışmalardan da sorumlu olduğunu, gerekli işlemin yapılıp bir mazbatayla Meclîs-i Vâlâ’ya gönderildiğini ve yeni mecliste yargılama işinin devlet memurları ile sınırlandırılarak bu görevin Mubakemât Dairesine verildiğini de eklemiştir. Devamında, Şûrâ-yı Devlet’in kuruluş aşamalarına değinen Taşkesenlioğlu; Sultan Abdülaziz ve ikinci kuşak Tanzimatçıların Fransa'dan mülhem daha demokratik adımlar atılması gerektiği görüşünü aktarmış ve 10 Mayıs 1868'de Şûrâ-yı Devlet ve Mecliss-i Abkâm-ı Adliye adıyla açılan meclislerle, yasama ve yarg1 güçlerinin birbirinden tekrar ayrıldığını belirtmiştir. Ardından, Meclîs-i Vâlâ-yı Ahkâm-1 Adliye'nin yasama gücünün Şûrâ-yı Devlet'e bırakıldığını ve başkanlığına Tuna Vilayeti Valisi Midhat Paşa'nın getirildiğini; yarg1 gücünün de Dîvân-1 Ahkâm-1 Adliye'ye bırakıldığını ve başkanlığına Cevdet Paşa'nın atandığını aktarmıştır. Yazar bu bölümde son olarak, Şûrâ-yı Devlet'in, Umûr-1 Mülkiye ve Zabıta ve Harbiye; Mâliye ve Evkâf; Adliye; Umûr1 Nâfiâ ve Ticaret ve Ziraat; Maarif olmak üzere beş daireye ayrıldığını ve Şûrâ-yı Devlet Tanz̨imât Dairesi'nden, 24 Eylül 1921'e kadarki son faaliyetine kadar oluşum ve değişim sürecini aktarmıstır (s. 240-265.).

Taşkesenlioğlu, kitabın "Sonuç” kısmında Meclîs-i Âlî̀-i Tanzîmât’ın Osmanlı modernleşme döneminde en yetkin kurum olduğunu; yasama, yürütme ve yargı uzuvlarının ayrılma çalışmalarına binaen ortaya çıkışının dikkate değer bir dönemi teşkil ettiğini ve bu sürecin I. Meşrutiyet Dönemi'nin alt yapısı olarak değerlendirilmesi gerektiğini ifade etmiştir. Bugünkü Damıstay’a temel teşkil eden Şûrâ-yı Devlet'e Meclîs-i Âlî-i Tanzîmât'ın görev ve sorumlukları bakımından öncülük ettiğini ifade eden yazar, eserde Meclîs-i Âlî-i Tanzîmât ve Şura-yı Devlet tüzüklerinin mukayesesi üzerinden bu fikrin daha iyi anlaşılacağını da ekleyerek, çalışmasının eksenini izah etmiştir. Ayrıca parlamentarižmin Osmanlı'daki teşekkülünün Meclîs-i Âlî-i Tanzîmât'a dayandı̆̆ını belirtmiştir. Devletin tanzimi, ıslahı ve halkın refahı adına diğer merkezi meclis çalışmalarının yetersizliğinin Meclîs-i Âlî-i Tanzîmât'in kuruluşuna neden teşkil ettiği; nitekim bu meclisin de adıyla müsemma olarak tüm Tanzimat hedeflerine dair çalışmaları yürüttüğü aktarılmıştır. Kuruluşunda etkili olan Mustafa Reşit Paşa'nın bürokrasi üzerinden siyasi manevralar yapmasının yansıdığı Meclîs-i Âlî-i Tanzîmât'ın aynı zamanda büyük devletlerin elçileri ve bu elçilerin desteklediği yabanc1 yatırımcıların müdahil olduğu ve olmak istediği bir mücadele sahası olduğu okuyucuya iletilmiştir. 
Bu reform meclisinin yetki alanına Meclîs-i Vâlâ ve Şûrâ-yı Devlet'in sahip olmadığını ifade eden Taşkesenlioğlu; kanunlaştırma hareketindeki bu kısmi özerklĭgin, Meclîs-i Âlî̀-i Tanzîmât'in faaliyet süresiyle sınırlı kaldığını aktarmıştır.

Çalışmamız hakkında bir değerlendirme yapacak olursak: Saltanat geleneğinin, şeriat adına İslamileştirilmesinin sekteye uğradığı, şeri hukukun etki alanının daraldığ1, adalet ve şeriat kavramlarının ayrılmaya başladığı Tanzîmât'la; hem taşradaki mütegallibeye karşı, hem yönetici elitlere karşı merkeziyetçi-modern bir devlet tesisi için hukuka dayalı bir idare ve eşitlik anlayışı tasavvur edilmişti. Tanzimat her şeyden önce çok hukukluluk tartışmalarına yapılan, tek hukuk savunusuydu. Osmanlı Devleti'nde teşkilat(yönetme) hukuku ile yarg1 (şeri) hukuku iç içeyken ve bu iki dinamik, pragmatik metotlarla birbirini dengelerken; Tanzimat, kanun yapma yönünü vurgulayarak, bu iki hukuku eşitlemek istemiş ve dönüşümlerini hedeflemiştir. Dolayısıyla padişah ve yöneticiler, hukuki bir nizama bağlanmış; bunun filî̀ sonucu ise bürokrasi üzerinden iktidarı sağlamak olmuş; kanunlar bu idealin gerçekleşmesinde aracı olan ve devamlılık sağlayan bir koruyucu niteliği taşımıștır. Bu bağlam üzerine incelediğimiz kitabın konusu olan Meclîs-i Âlî-i Tanzîmât; hukuk devleti tesisi doğrultusunda, yasama-yürütme-yarg1 fonksiyonlarının kendi alanlarını belirlediği bir sürecin ürünüdür. Osmanlı merkez teşkilatının bu ideal doğrultusunda dönüşümü, bürokratik reformlar, merkezî danışma meclisleri ve bürokratik yapıları hakkında arşivlerin yeterince tahkik ve mütalaa edilmemesi ise Tanzimat rükünlerini sistematik olarak incelememiz noktasında bir engeldir. Bu bağlamda Taşkesenlioğlu'nun, alandaki boşluğu dolduracak minvaldeki bu çalışması, Osmanlı Devleti'nin hemen her alanda reform hareketinde bulunduğu 1854-1861 sürecinde en etkin ve kismi özerk bir birim olan Meclîs-i Âlî-i Tanzîmât hakkında literatüre önemli katkılar sağlamaktadır. 